University of Nebraska - Lincoln

DigitalCommons@University of Nebraska - Lincoln

\title{
Post-disaster assessment of northeastern coastal region for the 2011 Sendai Earthquake and tsunami
}

\author{
Ruopu Li \\ University of Nebraska-Lincoln, ruopulee@yahoo.com \\ Shishi Liu \\ University of California-Santa Barbara, lius2@ornl.gov \\ Qingfeng Guan \\ University of Nebraska-Lincoln, qguan2@unl.edu \\ Yi Peng \\ University of Nebraska-Lincoln, ypeng2@unl.edu
}

Follow this and additional works at: https://digitalcommons.unl.edu/natrespapers

Part of the Natural Resources and Conservation Commons

Li, Ruopu; Liu, Shishi; Guan, Qingfeng; and Peng, Yi, "Post-disaster assessment of northeastern coastal region for the 2011 Sendai Earthquake and tsunami" (2011). Papers in Natural Resources. 354.

https://digitalcommons.unl.edu/natrespapers/354

This Article is brought to you for free and open access by the Natural Resources, School of at DigitalCommons@University of Nebraska - Lincoln. It has been accepted for inclusion in Papers in Natural Resources by an authorized administrator of DigitalCommons@University of Nebraska - Lincoln. 


\title{
Post-disaster Assessment of Northeastern Coastal Region for the 2011 Sendai Earthquake and Tsunami
}

\author{
Ruopu Li \\ School of Natural Resources \\ University of Nebraska-Lincoln \\ Lincoln, NE USA 68583 \\ rli@huskers.unl.edu
}

\author{
Shishi Liu \\ Geography Department \\ University of California-Santa Barbara \\ Santa Barbara, CA USA 93106 \\ shishi@umail.ucsb.edu
}

\author{
Qingfeng Guan, Yi Peng \\ School of Natural Resources \\ University of Nebraska-Lincoln \\ Lincoln, NE USA 68583 \\ \{qguan2; ypeng2\}@unl.edu
}

\begin{abstract}
The 2011 Sendai Earthquake has hit the north-east of Japan triggering a destructive tsunami that has caused extensive damage. A fast and effective post-disaster assessment is highly imperative for the recovery of this region. This study modeled the tsunami-affected areas of coastal Fukushima Prefecture using Landsat-7 ETM+ data and terrain analysis. The result shows that most of the coastal areas were significantly affected by the tsunami. The low-lying plains along the coast are particularly vulnerable to the tsunami.
\end{abstract}

Keywords- Sendai Earthquake and Tsunami, Sendai, tsunami, Fukushima, Landsat, NDVI, GDEM

\section{INTRODUCTION}

A magnitude 8.9 earthquake struck off the east coast of Japan on March 11 ${ }^{\text {th }}, 2011$ (2:46 p.m. local time), followed by an unprecedented devastating tsunami within several minutes. The tsunami waves swept into the coastal region west and south of the earthquake epicenter, and inundated the plains along the coast. The Japan Port and Airport Research Institute reported 4.1-23.6 $\mathrm{m}$ inundation height at tsunami-affected ports and airport through field survey [1]. The disaster caused tremendous property loss and casualties. Estimated damage amounts to $\$ 122-235$ billion, and more than 15,200 have been reported death or missing [2].

After the disaster, it is imperative to assess the tsunamiaffected areas and initiate recovery activities as soon as possible. Remote sensing, along with geographic information systems (GIS), can play key roles in the assessment and mitigation of natural disasters [3]. Remote sensing and GIS have been applied to tsunami responses assessment and flood mapping. For example, Landsat, SPOT, radar data, and SRTM were widely used to assess the damage for the 2004 SumatraAndaman Earthquake and Indian Ocean Tsunami [4]. Wang et al. [5] used Landsat-7 TM imagery and digital elevation model (DEM) to map flood extent in a coastal area of North Carolina, USA. Theilen-Willige [6] used remote sensing and GIS to detect the vulnerable areas to flooding and inundation by tsunamis. In many cases, satellite imagery is the only data source of the hard-hit and difficult-to-access areas at the early post-disaster stage when field survey data are often unavailable. The 2011 Sendai Tsunami is not an exception. The affected area was so widespread that the traditional field survey was ineffective. Also, deteriorating radiation leaks from the earthquake-stricken nuclear reactors [7] also make any onsite evaluation activities dangerous. In this case, the combination of remote sensing and geographic information systems (GIS) is currently a cost-effective and safe method to assess the Japan tsunami-affected areas.

This paper aims to delineate the tsunami-affected Japanese coastal area using Landsat-7 ETM+ imagery, DEM, and GIS. To conduct a fast and inexpensive evaluation of the affected areas, we utilized free Landsat imagery with $30-\mathrm{m}$ spatial resolution along with ASTER Global DEM.

\section{STUDY AREA}

The coastal region of Fukushima was selected as the study area, because this region was strongly affected by the March 11th tsunami and most of this region is free of clouds in ETM+ images before and after the tsunami. The study area is located at the northeastern Japan, approximately 135 kilometers southwestern of the earthquake epicenter (Fig. 1). Fig. 2 shows the inundated coastal area of Minamisoma City, Fukushima after the tsunami.

\section{DATA AND METHODS}

\section{A. Data Acquisition and Preprocessing}

Two scenes of Landsat-7 ETM+ images (Path/Row: 107/34) before and after the earthquake/tsunami were used in this study: Feb 24, 2011 and Mar 12, 2011. The images were acquired through the USGS Earth Resource Observation and Science Center (http://glovis.usgs.gov/). Atmospheric conditi-ons were clear for most parts of the study area, and a few visible clouds or hazes were present at the time of imagery acquisition. A problem with the quality of the imagery is the presence of scan lines, which was due to the failure of the Scan Line Corrector (SLC) on the Landsat satellite. We filled the scan line gaps 
using the Frame and Fill tool from the U.S. National Aeronautics and Space Administration (NASA) [8].

In addition to ETM+ imagery, ASTER Global Digital Elevation Model (GDEM) was also used in the analysis. ASTER GDEM is a product made by Japan's Ministry of Economy, Trade, and Industry (METI) and U.S. NASA. Compared with other DEM products (such as SRTM3 and GTOPO90), it features finer horizontal $(30 \mathrm{~m})$ and vertical resolution (1 $\mathrm{m}$ increment), global coverage, and free access [9] ( http://www.ersdac.or.jp/GDEM/E/2.html).

\section{B. Mapping Tsunami-affected Areas with Landsat-7 ETM+ Images}

An ETM+ image of February 24, 2011 before the Tsunami and an ETM+ image of March 12, 2011 after the Tsunami were used in this study. The images were georectified to UTM projection and digital number (DN) values were converted to reflectance using the Landsat preprocessing tool in ENVI software package. The images were then subset to the study area and the clouds on the images were masked out. Normalized Difference Vegetation Index (NDVI) was used to identify flood affected area:

$$
\mathrm{NDVI}=\left(\mathrm{R}_{\mathrm{INR}}-\mathrm{R}_{\mathrm{red}}\right) /\left(\mathrm{R}_{\mathrm{INR}}+\mathrm{R}_{\mathrm{red}}\right)
$$

in which $R_{I N R}$ represents the reflectance of band 4 and $R_{\text {red }}$ represents the reflectance of band 3 in ETM+ images. Several studies have shown that NDVI can be used to monitor and map inundation $[5,10,11]$. Unlike other land surface features, water is strongly absorbed in the near infrared region. Therefore, when a surface feature is inundated, its NDVI value changes considerably from the normal situation [12]. Wang et al. [5] observed that in the lower reaches of the Yangze River, the NDVI values for inundated surface features were negative while the value for non-inundated surface were commonly positive. However, in some other studies, NDVI values of inundated surface were observed to be positive [10]. In this study, we found that the NDVI values for most of the inundated area were negative, but for some inundated areas, such as the bank of a pond or possibly the area with shallow inundation depth, were slightly positive. In addition, the NDVI values for water bodies, such as lakes, ponds and rivers were always negative with or without inundation. The inundated areas were then determined as the area with positive NDVI values in the image of February 24 and with NDVI values smaller than 0.08 in the image of March 12. The threshold of 0.08 was determined arbitrarily based on the observations of NDVI values in the inundated area.

\section{Calibration using DEM}

In general, the NDVI-based spectral analysis can identify most of the tsunami-affected areas. However, in comparison with pre- and post-disaster images, some errors were identified. For example, some cloud shadows were mistakenly captured by NDVI as flooded area (Fig. 3a), since the NDVI of the cloud shadows were usually below the threshold of 0.08 . NDVI also underestimated some inundated area (Fig. 3b), such as some coastal woodland and the edges of ponded water.

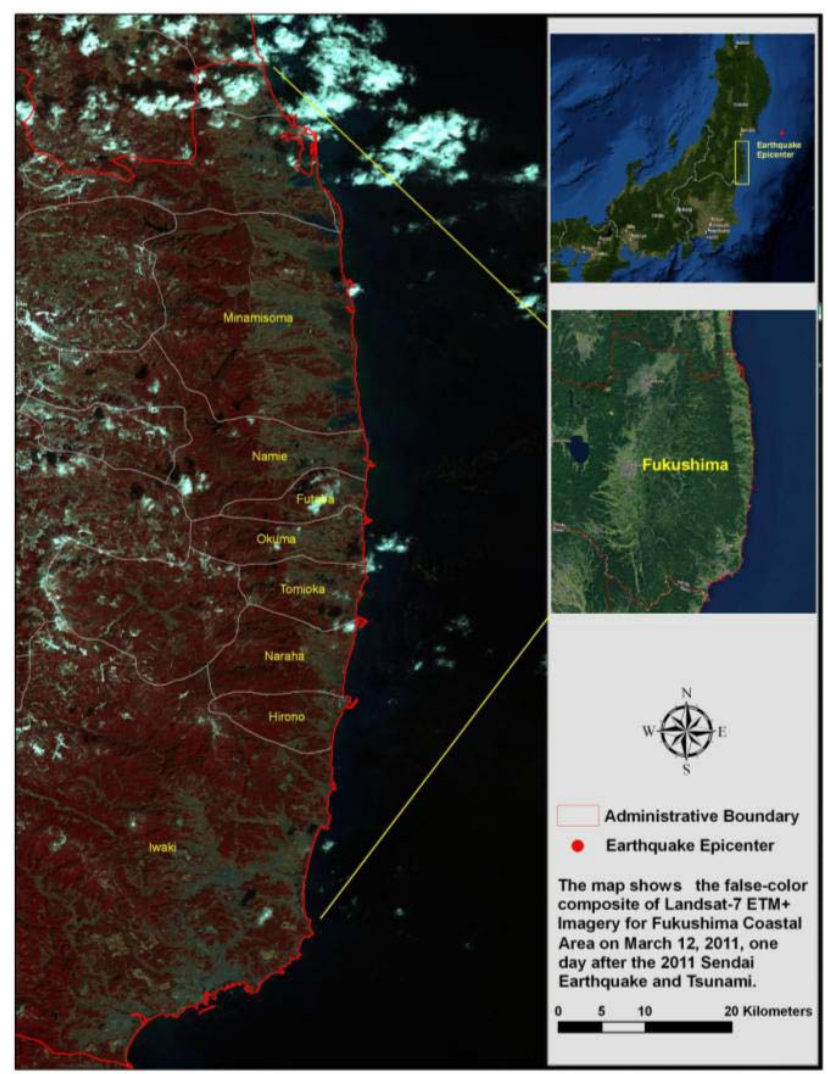

Figure 1. Landsat Image of Fukushima Coast, Japan on March 12th , 2011.

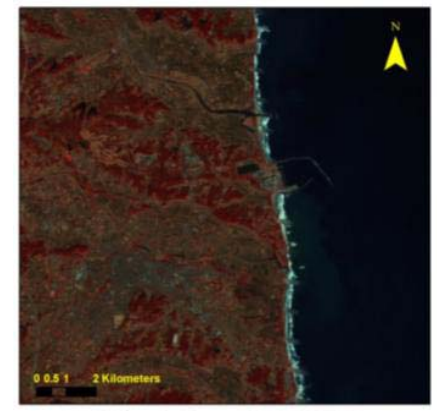

(A) Before the Tsunami (Feb 24, 2011)

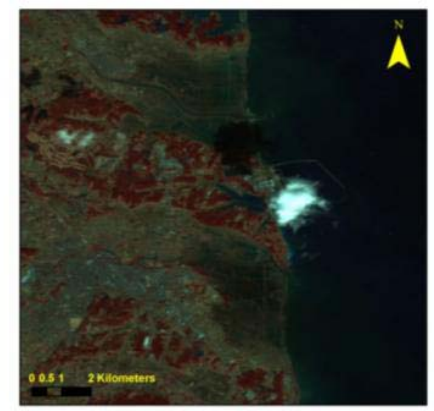

(B) After the Tsunami (March 12, 2011)
Figure 2. Tsunami-affected coastal areas near Minamisoma City, Fukushima

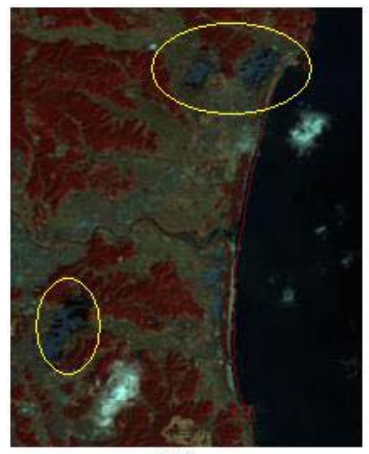

(A)

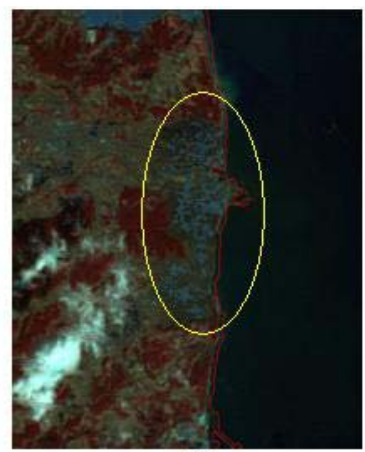

(B)
Figure 3. Areas not accurately classified based on NDVI (grey blue areas were modeled tsunami-affected area based on NDVI). 
DEMs and GIS have been widely used to aid remotely sensed flood mapping. For example, Wang et al. [5] used DEM data to identify flooded areas under forest canopies, which cannot be captured using remote sensing. In this study, we used the following method to calibrate the NDVI-based inundated areas (Fig. 4). Two elevation thresholds were selected using the following methods to eliminate the pixels that were incorrectly classified as inundated areas and complement the areas that were not captured by NDVI. Firstly, the ASTER GDEM was clipped for the NDVI modeled areas. Since the elevation of the tsunami-affected extents is dominantly below $10 \mathrm{~m}$ (Fig. 5), all pixels with an elevation above $9 \mathrm{~m}$ were treated as nontsunami-affected area and filtered using GIS. Considering some low-lying inundated areas were not well captured, we reclassified the areas of northern Fukushima below $4 \mathrm{~m}$ as inundated, and the southern areas below $2 \mathrm{~m}$ as flood-affected. The difference in selected elevation thresholds for northern and southern Fukushima was due to the distance from the earthquake epicenter. Low-lying coastal areas close to earthquake epicenter may be more vulnerable to tsunami inundation. Finally, we combined filtered NDVI-based areas and low-lying land as the tsunami-affected extent.

\section{RESULTS AND DISCUSSIONS}

The total tsunami-affected area is shown in Fig. 6. The total tsunami-affected area amounts to $62.41 \mathrm{~km}^{2}$. Among 11 towns/cities along the coast, Minamisoma, Soma and Shinchi were most heavily affected (Table 1). This may be due to the fact that they are closer to the earthquake epicenter.

One of the limitations in this study is lacking current ground truth to validate our results. The validation of the map was conducted by a comparison with post-disaster GeoEye images shared through Google Earth (available through Japan Sendai Earthquake Data Portal, http://cegrp.cga.harvard.edu/ japan/?q=content/home). Based on our map comparison, the modeled tsunami-affect area can well correspond with the land area engulfed during the tsunami. Other limitations may also affect the accuracy of our analysis. For example, the scan line problem of the original Landsat-7 ETM+ images may cause uncertainties on those missing strips of pixels. The 7-15 m vertical accuracy [9] of GDEM may also bring uncertainties to our modeled tsunami-affected area.

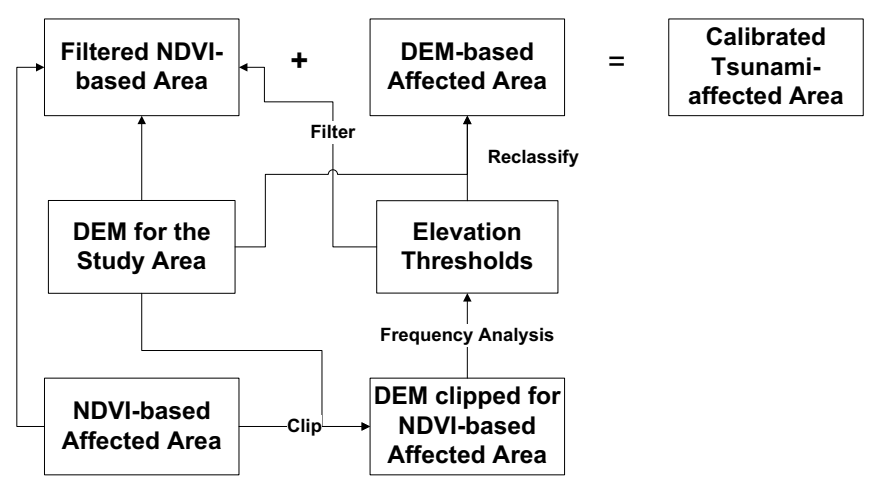

Figure 4. The procedure to calibrate tsunami-affected areas using DEM.

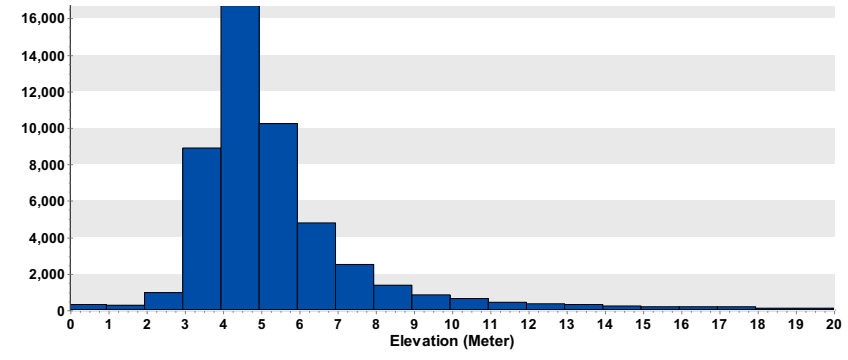

Figure 5. Frequency of elevation values that fall in the NDVI-modeled affected area.

TABLE I. AFFECTED AREA FOR TOWNS/CITIES OF FUKUSHIMA PREFECTURE ALONG THE COAST

\begin{tabular}{|c|c|}
\hline Town/City & Affected Area $\mathbf{( k m}^{\mathbf{}} \mathbf{)}$ \\
\hline Futaba & 1.19 \\
\hline Hirono & 0.66 \\
\hline Iwaki & 2.54 \\
\hline Minamisoma & 23.77 \\
\hline Namie & 3.57 \\
\hline Naraha & 1.04 \\
\hline Nishiaizu & 0.28 \\
\hline Okuma & 1.15 \\
\hline Shinchi & 5.41 \\
\hline Soma & 22.01 \\
\hline Tomioka & 0.79 \\
\hline
\end{tabular}

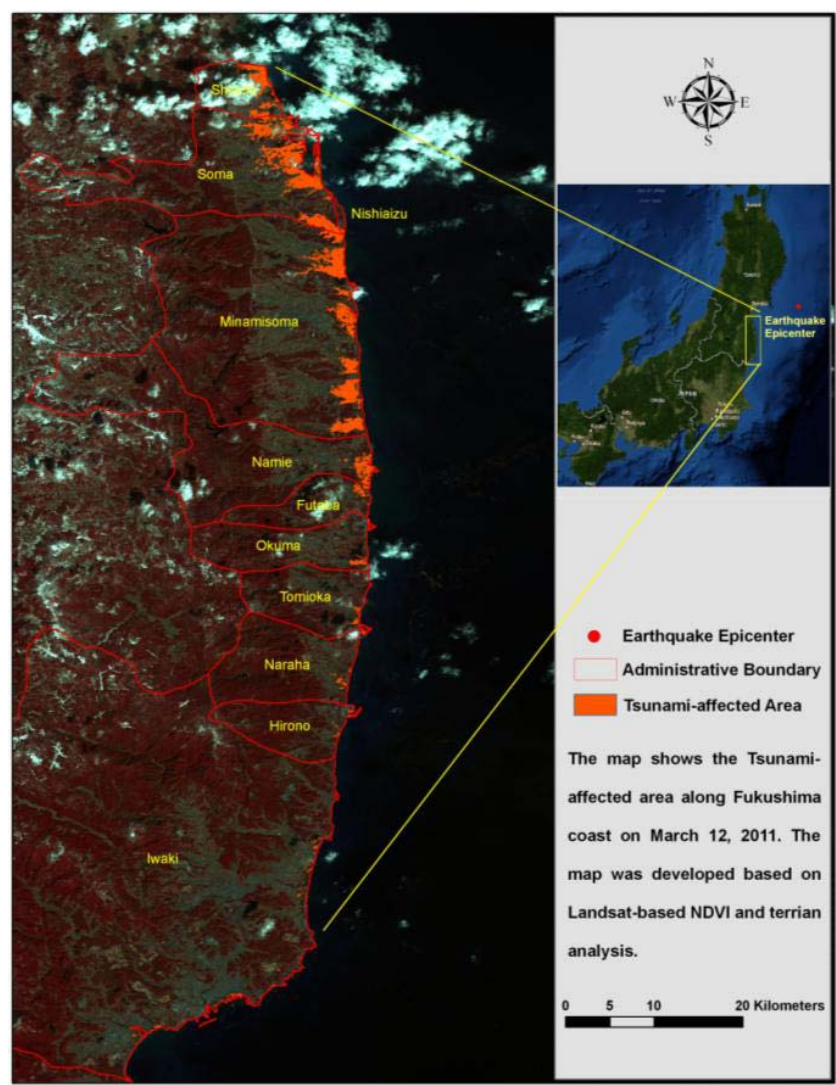

Figure 6. Tsunami-affected areas along the Fukushima coast. 


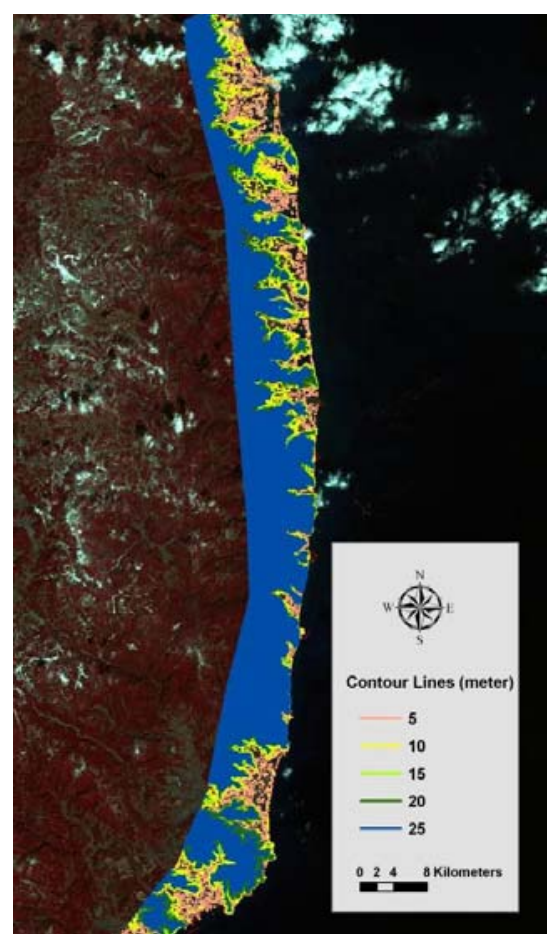

Figure 7. Topography of the Fukushima coastal areas.

Fig. 7 exhibits the elevation contours along the Fukushima coast. Based on a comparison of Fig. 6 and Fig. 7, the tsunamiaffected area was closely related to the topography. The low and flat plains along the Japanese coast southwest of the earthquake epicenter are particularly vulnerable to tsunamis. This is similar to the observation in the west coast of Myanmar after 2004 Indian Ocean Tsunami, where low-elevation areas were highly susceptible to tsunami flooding. Also, the distance from earthquake epicenter may be another factor affecting the tsunami inundation. As shown in Fig. 6 and Fig. 7, the southern low-lying areas did not show similar inundation to the northern part of the study area.

\section{CONCLUSIONS}

This study delineated the tsunami-affected coastal areas using remote sensing and GIS techniques. Landsat-7 ETM+ and ASTER GDEM datasets provide an inexpensive and effective way to map the affected areas. Analysis demonstrated that costal Fukushima was significantly affected by the March 11 Sendai Tsunami. The low and flat plains along the coast are particularly vulnerable to the tsunami disasters. This study also showed that using free or low-cost satellite imagery can improve disaster readiness, provide timing responses, and raise public awareness of disasters.

\section{ACKNOWLEDGMENT}

The authors gratefully acknowledge the Japan Sendai Earthquake Data Portal, hosted by the Center for Geographic Analysis at Harvard University for the geospatial data assisting our analysis.

\section{REFERENCES}

[1] Port and Airport Research Institute (PARI), "Executive summary of urgent field survey of earthquake and tsunami disasters by the 2011 off the Pacific coast of Tohoku Earthquake," March 2011, online retrieved at http://sendai. hmdc.harvard.edu/portal/other_distro/PARI_Field_Survey_02.pdf.

[2] World Bank, "The recent earthquake and tsunami in Japan: implications for East Asia," East Asia and Pacific Economic Update, vol.1, pp: 1-2, 2011.

[3] M. R. Teeuw, "Introducing the remote sensing of hazardous terrain," Geol. Soc., London, vol. 283, pp:1-3, 2007.

[4] J. A. Kelmelis, L. Schwartz, C. Christian, M. Crawford, and D. King, "Use of geographic information in response to the Sumatra-Andaman Earthquake and Indian Ocean,” Photo. Eng. \& Remote Sen., vol.72, pp: 862-876, 2006.

[5] Y. Wang, J. D. Colby, and K. A. Mulcahy, "An efficient method for mapping flood extent in a coastal floodplain using Landsat TM and DEM data," Int. J. Remote Sen, vol. 23, pp:3681-3696, 2002.

[6] B. Theilen-Willige, "Natural hazard assessment of SW Myanmar-a contribution of remote sensing and GIS method to the detection of areas vulnerable to earthquakes and tsunami/cyclone fooding," Sci. Tsunami Hazards, vol. 28 , pp:108-128, 2009.

[7] Mail Foreign Service, "Exclusion zone around stricken Japanese nuclear plant widened over fears reactor core may be cracked," March 2011. Online retrieved at http://www.dailymail.co.uk/news/article-1369993/Japan-nuclearmeltdown-Fukushima-plant-exclusion-zone-widened-reactor-fears.html.

[8] R. Irish, "Frame and fill tool, Version 1.0," Greenbelt, MD: NASA Goddard Space Flight $\bar{C}$ enter, 2009

[9] A. Hirano, R. Welch, and H. Lang, "Mapping from ASTER stereo image data: DEM validation and accuracy assessment," ISPRS J. Photo. \& Remote Sen., vol. 57, pp: 356-370, 2003.

[10] I. Barton, and J. Bathols, "Monitoring floods with AVHRR," Int. J. Remote Sen. vol. 10, pp: 1873-1892, 1989.

[11] R. Brakenridge, and E. Anderson, "MODIS-based flood detection, mapping, and measurement: the potential for operational hydrological applications. Transboundary floods: reducing risks through flood management," Springer Verlag, 2006, pp: 1-12.

[12] J. Sanyal, and X. X. Lu, "Application of remote sensing in flood management with special reference to Monsoon Asia, a review," Natural Hazards, vol. 33, pp: 283-301, 2004. 